Working

Paper

Department

of Economics

$\mathrm{Ca}^{\prime}$ Foscari University of

Venice

Giovanni Millo

Giacomo Pasini

Does Social Capital Reduce

Moral Hazard? A Network

Model for Non-Life

insurance demand 


\title{
Does Social Capital Reduce moral hazard? A network model for non-life insurance demand
}

\author{
Giovanni Millo \\ Research Dept., Generali SpA \\ and \\ Department of Economics and Statistics, University of Trieste \\ Giacomo Pasini \\ School for Advanced Studies in Venice \\ and \\ University of Venice
}

First draft: December 2006

This version: August 2007

\begin{abstract}
We study the effect of moral hazard involved in non market contracts on the demand for marketed contracts. We extend the Arnott and Stiglitz model on the coexistence of market and non-market insurance to allow for the presence of Social Capital as a determinant of the severity of moral hazard in informal contracts. We provide a rigorous definition of Social Network and Social Capital by means of an equilibrium concept typical of the Network literature. Such a formal approach gives us a clear guidance for measuring Social Capital and validate the model on empirical data. The model is estimated on a panel dataset, supporting our claim that Social Capital increases the demand for non-life insurance. We test for the presence of spatial correlation, and conclude that the spatial structure of demand for non--life insurance contracts is determined by the spatial distribution of Social Capital.
\end{abstract}

Keywords

Insurance, Social Capital, Network stability, Spatial Panel data model

JEL Codes

C21, D85, G22, Z13

Address for correspondence:

Giacomo Pasini

Department of Economics

Ca’ Foscari University of Venice Cannaregio 873, Fondamenta S.Giobbe 30121 Venezia - Italy

Phone: (++39) 0412349125

Fax: $(++39) 0412349176$

e-mail: giacomo.pasini@unive.it

This Working Paper is published under the auspices of the Department of Economics of the Ca' Foscari University of Venice. Opinions expressed herein are those of the authors and not those of the Department. The Working Paper series is designed to divulge preliminary or incomplete work, circulated to favour discussion and comments. Citation of this paper should consider its provisional character.

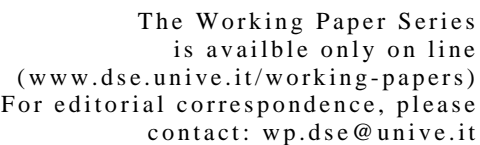




\section{Does Social Capital reduce moral hazard? A network model for non-life insurance demand ${ }^{1}$}

\section{Introduction}

Social Capital is a concept not limited to sociology: during the last 20 years it spread out and has been used across almost all social sciences. Despite such a great interest and huge amount of research on it, it's still a suggestive word that reminds of many different but related research fields, rather than a precise concept. Further on, the study of social capital has a lot to do with Italy: the seminal book by citePutnam:93 about democracy and institutions' efficiency across Italy is a source of overwhelming empirical evidence on the relevance of social capital in Italian social life. Focusing on economics, recently Guiso et al. (2004) found that social capital influences the asset allocation choices of Italian households: they started from the idea that any financial contract involves trust, which is strongly correlated to Social Capital, and found empirical results on this relation.

Our question is whether it matters also on individual choices about insurance expenditure. In particular, we are interested in demand for non-life insurance contracts. While life insurance can be assimilated to pension funds and other financial assets in terms of economic rationale - it's an investment which gives a return - for non-life insurance things are different. Households buy a non-life insurance contract to avoid the risk of suffering losses in some future state of the world: they pay a fixed price (the premium) to transfer money from a future uncertain state of the world to a certain one. Arnott and Stiglitz (1991) set up a model where together with market insurance, individuals can enter in non-market mutual insurance contracts. In their model the role played by non market insurance is related to peer monitoring: if informational asymmetry between the insurer and the customer still holds in non-market contracts, they are dysfunctional and non-market insurance displaces market contracts reducing social welfare. Vice versa, if individuals can observe other individuals' effort, non-market contracts are welfare enhancing since they provide extra insurance coverage at the market price set by the insurance company. What they call peer monitoring is actually the severity of moral hazard in non-market agreements. We will investigate the relation between moral hazard involved in non market insurance contracts and demand for market insurance. We will also formally link moral hazard and social capital, concluding that social capital itself increases the aggre-

\footnotetext{
${ }^{1}$ Authors wish to thank Stefano Magrini, Piero Gottardi, Paolo Pin, Piero Tedeschi, Gaetano Carmeci and participants to seminars in Catholic University of the Sacred Heart, Milano; University of Trieste; QED meeting 2007, Venezia; ICEE conference, Rimini; 'Reciprocity: theory and evidence' conference, Verbania; Spatial Econometrics Conference 2007, Cambridge
} 
gate demand for insurance. A careful definition of Social Capital and its role in the model allows us to test our conclusions empirically.

Previous studies on Italy leave space for such a model. Millo and Lenzi (2005) found that the Italian insurance market exhibits spatial heterogeneity and spatial correlation at the province level even after controlling for a number of demographics. If heterogeneity in the diffusion of insurance contracts is due to differences in the degree of Social Capital, it is reasonable to think that its diffusion does not follow administrative province boundaries: therefore, our explanation is coherent with the presence of spatial correlation at the province level. The social capital interpretation is suggestive also for another reason: Durlauf and Fafchamps (2004) point out that a possible role for social capital in economic models is to limit market inefficiencies when institutions fail to resolve them: In Italy family ties are frequently substitutes for inefficient institutions. Religious (mainly catholic) communities as well as some other professional and voluntary associations play a role in supplementing part of the social welfare not provided by the State: disabled and elder people assistance or scholarships are some examples.

We estimate our model on a panel database of Italian provinces, explicitly taking spatial correlation into account. Spatial panel estimation techniques, first outlined in Anselin (1988), have not become a standard yet in the literature because of computational difficulties. Based on the comprehensive treatment of Elhorst (2001), we develop new procedures in the R language for maximum likelihood estimation of spatial autoregressive and spatial error panel models.

The paper is structured as follows: the second section describes the economic model. The following one extends it to provide a formal definition of Social Capital and to include it as a determinant of the demand for market insurance. Such an extension will be done within a Network approach. Before going to empirical validation of our model we describe the dataset. The fifth section is dedicated to the definition of an empirical measure for Social Capital. The sixth part describes the estimation procedure and results. In the seventh section we carry on the analysis of the spatial structure of the model. Conclusions are drawn in the final section.

\section{The model}

Arnott and Stiglitz (1991) were interested in the general equilibrium and welfare effects of non market insurance and peer monitoring. Their model provides the background to study the effect of moral hazard and therefore - as we will see in the next section - of Social Capital on the demand for market insurance.

The starting point is the canonical moral-hazard model without non market insurance. There is a single and fixed damage accident. The probability 
of its occurrence, $p(e)$, is strictly convex and decreasing in the individual's effort at accident avoidance, $e$, which is not observable to the insurer. Individual wealth is $w$, the damage caused by the accident $d$. Individuals pay a premium $\beta$ and receive a net payout $\alpha$ in case the accident occurs. Utility has the following form:

$$
\begin{aligned}
E U^{M} & =(1-p(e)) U(w-\beta)+p(e) U(w-d+\alpha)-e \\
& =(1-p(e)) u_{0}+p(e) u_{1}-e
\end{aligned}
$$

$E U^{M}$ is well behaved (increasing and strictly concave) and separable, meaning in both the states of the world it is strongly separable in $w$ and effort; disutility of effort is event independent, the effort is measured by the disutility it causes and utility of consumption $u(\cdot)$ is event independent. At the competitive constrained equilibrium, the insurer offers less than full insurance to induce the clients to augment their effort at accident avoidance, i.e. $d-\alpha>\beta$, meaning that the ordering of states of the world in terms of utility is not altered: the wealth reduction in the "good" state of the world, $\beta$, must be lower than the wealth reduction in the "bad" state, $d-\alpha$. This equilibrium is stable only if clients purchase no additional insurance. Such a condition must be enforceable by the insurer. This exclusivity condition is not far from what happens in the real world: insurance companies cannot force their clients to buy just one contract, but they ask them to reveal which other contracts they have covering the same risk, and in case of accident occurrence payout is divided proportionally among insurers.

Non-market insurance is introduced as follows: a couple of symmetric individuals, $i$ and $j$, agree that if one of them has an accident and the other doesn't, the latter will transfer $\delta$ to the former. Each of them realizes that the extra insurance will pay out if they have an accident and their partner doesn't, therefore their expected utility changes:

$$
\begin{aligned}
E U_{i}^{N M O}= & \left(1-p\left(e_{i}\right)\right)\left(1-p\left(e_{j}\right)\right) U(w-\beta)+p\left(e_{i}\right) p\left(e_{j}\right) U(w-d+\alpha) \\
& +\left(1-p\left(e_{i}\right)\right) p\left(e_{j}\right) U(w-\beta-\delta) \\
& +p\left(e_{i}\right)\left(1-p\left(e_{j}\right)\right) U(w-d+\alpha+\delta) \\
& -e_{i} \\
= & \left(1-p\left(e_{i}\right)\right)\left(1-p\left(e_{j}\right)\right) u_{0}+p\left(e_{i}\right) p\left(e_{j}\right) u_{1} \\
& +\left(1-p\left(e_{i}\right)\right) p\left(e_{j}\right) u_{2}+p\left(e_{i}\right)\left(1-p\left(e_{j}\right)\right) u_{3}-e_{i}
\end{aligned}
$$

Individuals maximize their utility considering $\alpha$ and $\beta$ and therefore the contract's price $q=q(\alpha, \beta)$ as fixed: they perceive that if they enter a mutual contract they can buy extra insurance at the market price $q$. They choose $\delta$, which is the premium but also the payoff of the non-market agreement. Further on each of them considers her partner as rational and assumes she will choose the level of effort which maximizes her own utility. 
If each individual does not observe the others' effort, the exclusivity provision cannot be enforced: each client pays an extra premium $\delta$ if the partner has an accident and he doesn't, while he receives an extra payoff $\delta$ in the opposite case. It is optimal for them to reduce the effort while the insurance company is still offering the same contract. This is a partial equilibrium result since it doesn't consider the reaction of insurance companies to agents' behavior. In a General Equilibrium context the company knows that the required level of effort for the offered contract cannot be enforced: non market insurance crowds out market insurance and individuals substitute insurance provided by a risk neutral insurer with that provided by a risk averse one. Individual's expected utility, $E U^{N M U}$, is lower than without non-market insurance.

Vice versa, the authors show that if individuals can observe perfectly each other's effort, it is optimal for them to provide non market insurance up to full coverage to augment the risk sharing opportunity. Individuals choose $\delta$ and $e_{i}$ given $q(\alpha, \beta)$. Again each of them assumes peers entering non-market agreements to be rational, therefore the optimal level of effort will be the same for everybody: as in the previous case, $e_{i}=e_{j} \Rightarrow p\left(e_{i}\right)=p\left(e_{j}\right)$. Then, (2) simplifies to

$$
E U^{N M O}=(1-p)^{2} u_{0}+p^{2} u_{1}+p(1-p)\left(u_{2}+u_{3}\right)-e
$$

The utility maximizing non-market agreement is $\delta^{*}=(d-\alpha-\beta) / 2$, which brings coverage up to full insurance. Furthermore, substituting $u_{2}$ and $u_{3}$ in (3) and taking the derivative it can be proved that expected utility is increasing in $\delta$ between 0 and the utility-maximizing $\delta^{*}$.

Up to now we poited out that the presence of non-market agreements with perfect peer monitoring unanbigously reduces risk, since it augments the coverage available to individuals. Without peer monitoring this risk reduction induces individuals to reduce effort, thus displacing the insurance company, which is not able anymore to enforce a positive level of effort. The effort reducing effect of the extra coverage is present even with perfect peer monitoring, but it is contrasted by the absence of moral hazard: therefore a positive value of $\delta$ implies a positive level of $e$. Furthermore, from first order conditions, it is relatively easy to prove that the effort is not only positive but also increasing in $\delta$ between 0 and the optimal level $\delta^{*}$ as long as $p(e)<\frac{1}{2}^{2}$. This is due to the fact that as $\delta$ increases individuals become less selfish in their choice of effort. Thus, non market agreements in this case have two opposite effects on $e$. Arnott and Stiglitz (1991) prove the following proposition:

\footnotetext{
${ }^{2}$ Such a condition is reasonable: individuals want to insure against events with high losses $d$ but small probability $p$
} 
Proposition 1 Given the contract offered by the insurance company $q=$ $q(\alpha, \beta)$, if $p<\frac{1}{2}$ at equilibrium (i.e. if $\left.\delta=(d-\alpha-\beta) / 2\right)$, the effortincreasing effect of peer monitoring is higher than the effort-reducing effect of extra coverage.

The insurance company won't be displaced: it maximizes its expected utility with respect to $\beta$ and $\alpha$ under the zero profit condition $\alpha=\frac{1-p}{p} \beta$ and assuming that individuals maximize their own utility (i.e., $e=e^{*}$ and $\left.\delta=\delta^{*}=(d-\alpha-\beta) / 2\right)$.

We can now prove that non-market agreements are welfare enhancing, i.e. $E U^{M}<E U^{N M O}$. From (1) and (3),

$$
\begin{aligned}
(1-p) u_{0}+p u_{1}-e & <(1-p)^{2} u_{0}+p^{2} u_{1}+p(1-p)\left(u_{2}+u_{3}\right)-e \\
u_{0}+u_{1} & <u_{2}+u_{3} \\
u_{0}-u_{2} & <u_{3}-u_{1} \\
u(w-\beta)-u(w-\beta-\delta) & <u(w-d+\alpha+\delta)-u(w-d+\alpha)
\end{aligned}
$$

The inequality holds since utility is strictly concave and $\beta<d-\alpha$ due to moral hazard between the market insurer and clients. Such a result holds also once heterogeneity among individuals is introduced. Insurers offer different contracts based on observed characteristics of individuals such as age or marital status and on past statistics as loss ratios in a particular region ${ }^{3}$. What they are not able to do, due to information asymmetry, is to offer different contracts based on individual effort. The result by Arnott and Stiglitz tells us is that if the probability of accident occurrence is small, for any contract offered $\alpha, \beta$ and for any positive level of non-market coverage $\delta$ up to $\delta^{*}$, individual expected utility is higher than without non market agreements:

$$
E_{j}^{N M O}\left[U \mid \boldsymbol{X}_{j}\right]>E_{j}^{M}\left[U \mid \boldsymbol{X}_{j}\right]
$$

where $\boldsymbol{X}_{j}$ is a vector of observable individual characteristics, $E U^{N M O}$ is expected utility with non market contracts and perfect peer monitoring, $E U^{M}$ is expected utility with only market insurance.

Up to now we briefly outlined the main results of Arnott and Stiglitz (1991). We need a further step: while the authors were interested in the welfare effects of non-market agreements, we want to investigate how the demand for insurance changes if non market agreements are available. While a thorough investigation of properties of the demand function given a general utility is beyond the scope of the paper, we can restrict the shape of individual utility functions and of contracts offered by insurance companies

\footnotetext{
${ }^{3}$ the loss ratio for a type of accident is the ratio between claims paid and premium income.
} 
in order to have clear empirical implications, at the price of reasonable and usual assumption in the applied literature on insurance.

First of all, we can assume that insurance firms discriminate on the basis of all observable characteristics of agents and thus conditional on a set of demographics $\boldsymbol{X}$ potential client differ only by their effort. Thus, the following results can be thought of as valid for an homogeneous population or, given a population in which individuals differ along the dimension of $\boldsymbol{X}$ and of effort, the same results are all conditional on $\boldsymbol{X}$. Then for the remaining of the section we assume without loss of generality that individuals are all identical.

Drowing from the analytical treatment of moral hazard models in Arnott and Stiglitz (1988), it can be proved that:

Proposition 2 If expected utility function is separable, i.e. it falls in the class

$$
E U=(1-p(e)) U(w)+p(e) U(w-d)-e
$$

and if disutility of effort is event independent, the effort is measured by the disutility it causes, utility of consumption $U(\cdot)$ is event independent and

$$
\lim _{e \downarrow 0} \frac{(\partial p / \partial e)^{3}}{\partial^{2} p / \partial e \partial e}>-\infty
$$

then demand for insurance decrease with the price of insurance and increase with effort.

From the differentiation of the first-order conditions of the individual's effort choice problem the proposition can be proved to hold but for discontinuity points in the price-consumption line, which is the locus of utility maximizing linear contracts, i.e. contracts in which $q=\frac{\beta}{\alpha}$.

A sufficient condition for this line to be everywhere continuous is convexity of indifference curves. The last assumption of the proposition fullfil this requirement: the limit condition implies that $p$ is not too responsive to the effort $e$ (i.e., $p^{\prime}$ is low) and the curvature is high enough (i.e. $p^{\prime \prime}$ is high) at any point $(\alpha, \beta)$. An example of such a $p(e)$ is $p(e)=\bar{p}-e^{\gamma}$, where $\gamma>\frac{1}{2}$ : if individual put no effort on accident avoidance $p(e)=\bar{p}$, then the probability of suffering a wealth loss $d$ is decreasing with a power function of the effort.

Thus we restricted the utility function of individuals. The next step is to set conditions on strategies available to the other players, i.e. the insurance companies. First, we restrict contracts offered to be linear, i.e. $q=\frac{\beta}{\alpha}$. Market insurance contracts are exclusive, meaning that agents can sign just one contract with one insurance firm to cover a given risk. Further more, insurance market is competitive and companies set the price in order to make zero profit. Therefore at equilibrium 


$$
q=\frac{\beta}{\alpha}=\frac{p(e)}{1-p(e)}
$$

Separability, convexity of indifference curves, linear pricing and zero profit characterize equilibria. While it is possible to prove that an equilibrium with linear pricing always exists (see Arnott and Stiglitz (1988) for details), it may entail corner solutions, i.e. zero insurance or positive profits. Thus, for the sake of simplicity we concentrate on internal solutions, i.e. on equilibria characterized by positive insurance $(\beta>0, \alpha>0)$ and zero profits.

Proposition 2 states that insurance demand depends on effort $e$ and insurance price $q$, which are the choice variables respectively of agents and firms. If non-market agreements are not available, agents choose $e=\tilde{e}$ to maximize their expected utility considering $\tilde{q}$ as given. On the other hand firms internalize agents' best responses while pricing the contract, thus $q=\tilde{q}$ is the best response to $\tilde{e}$.

If agents can enter non market agreements which do not involve moral hazard, equilibrium effort and price changes. Agents consider the price offered $q^{*}$ as given, but they can choose not only $e$, but also the extra coverage characterizing the informal agreement $\delta$. We just saw that at equilibrium agents will agree upon $\delta^{*}=\left(d-\alpha^{*}-\beta^{*}\right) / 2$ such that they reach full insurance. Arnott and Stiglitz result reported in proposition 1 states that if $p<\frac{1}{2}$ the equilibrium effort $e^{*}$ is higher than the effort agents would have put without non market agreements, given $q^{*}$. As without non market agreements, insurance firms anticipate agents' choices $e^{*}, \delta^{*}$ in order to set the price $q^{*}$.

Therefore, we can conclude that:

Proposition 3 Given $\alpha>0, \beta>0$, if there exists an equilibrium without non market agreements $E_{0}$ and one with non market agreements and no moral hazard involved in those agreements $E_{1}$; if $p<\frac{1}{2}$; if the insurance company can offer only linear contracts and if assumptions of proposition 2 hold, then demand for market insurance in $E_{1}$ is higher than in $E_{0}$

The proof is straightforward: if $E_{0}$ and $E_{1}$ exist and $p<\frac{1}{2}$ holds than proposition 1 holds and the effort level $e$ in $E_{1}$ is higher than in $E_{0}{ }^{4}$. Since price is linear $q=\frac{\beta}{\alpha}$ is fixed. Then, since assumptions of proposition 2 hold, $q$ is fixed and $e$ is higher in $E_{1}$, market insurance demand is higher when informal contracts (without moral hazard involved in them) are available.

Proposition 3 deliver us an empirical implication about insurance demand only if the insurance company do not observe informal agreements, or if anyway it doesn't internalize it when setting the price $q$. If this is not the case $E_{0}$ and $E_{1}$ cannot exist at the same time: being $E_{0}$ the starting

\footnotetext{
${ }^{4}$ Note that we have to assume existence of those equilibria since linear pricing lead always to an equilibrium, but it could involve $\alpha=0$ or $\beta=0$.
} 
equilibrium, once informal insurance become available, the insurance firm would change $q$ in order to account for $\delta$.

Note that the way we modelled informal agreements implies a hidden assumption: once $i$ and $j$ enter the non market insurance contract, they can choose the level of effort to put on it but they must respect the contract. In other words, we assume that $i$ will transfer $\delta^{*}$ to $j$ everytime $j$ has an accident and $i$ doesn't, without deviations. Given the informal nature of the agreement this assumption may not be innocuous. A possible extention to relax it could be to consider $\delta$, the transfer on which $i$ and $j$ agree upon, as uncertain, and rewrite the model in terms of expected $\delta$. Our claim is that such an extension would complicate the expression of expected utility and the algebra stemming from it, while the main implications of the model would not change.

There is still something to do in order to achieve a testable implication: we would like to discriminate peers of individuals endowed with non-market agreements and to measure the severity of moral hazard within those communities. Moral hazard depend on peer monitoring, i.e. on reciprocal observability of the effort but also on the duration of the partnership, the level of trust between individuals entering the agreement, the severity of punishment when deviating from an agreement, the power of reputation and social pressure: in one word, the severity of moral hazard depends on the stock of social capital a community is endowed with.

\section{A network-based definition of Social Capital}

As already pointed out in the introduction, there isn't a clear-cut definition of Social Capital. It is an elusive concept that declines into particular meanings depending on the context where it is used. Social Capital is a suggestive idea, but in order to have a testable model we need to formalize this concept. Durlauf and Fafchamps (2004) point out as a common feature of many definitions of Social Capital the focus on interpersonal relationships and social networks. This is the reason why we use a network approach proposed by Vega-Redondo (2006).

Suppose that pairs of individuals that enter a non market insurance agreement with a given $\delta$ can choose in each period whether to put an effort $e_{N M U}$, which is the one with moral hazard in the Arnott Stiglitz framework, or $e^{N M O}$, effort without moral hazard. If expected utility is decreasing in the effort, such a game is a Repeated Prisoner's dilemma. From (2),

$$
\begin{aligned}
\frac{\partial E U^{i}}{\partial e_{i}}= & {\left[-\left(1-p\left(e_{j}\right)\right) u_{0}+p\left(e_{j}\right) u_{1}\right.} \\
& \left.-p\left(e_{j}\right) u_{2}+\left(1-p\left(e_{j}\right)\right) u_{3}\right] p^{\prime}\left(e_{i}\right)-1 \\
= & {\left[\left(u_{3}-u_{0}\right)\left(1-p\left(e_{j}\right)+\left(u_{1}-u_{2}\right) p\left(e_{j}\right)\right] p^{\prime}\left(e_{i}\right)-1\right.}
\end{aligned}
$$


which is decreasing in $e_{i}$ if $\beta+\delta<d-\alpha-\delta$, i.e. the total cost of insurance, $\beta+\delta$ must be lower than the loss suffered when the accident occurs. If this condition holds (together with $p(e)<\frac{1}{2}$ ), the game rewritten in strategic form with expected utilities as payoffs is of the Prisoner's dilemma type (see figure 1). Since marginal utility is decreasing in the (own) effort, for individual $i$ we can write

$$
\begin{aligned}
& E U_{i j}^{H}=E U\left(e_{i}=e_{N M U}, e_{j}=e^{N M O}\right)>E U_{i j}^{N M O} \\
& E U_{i j}^{L}=E U\left(e_{i}=e^{N M O}, e_{j}=e_{N M U}\right)<E U_{i j}^{N M U}
\end{aligned}
$$

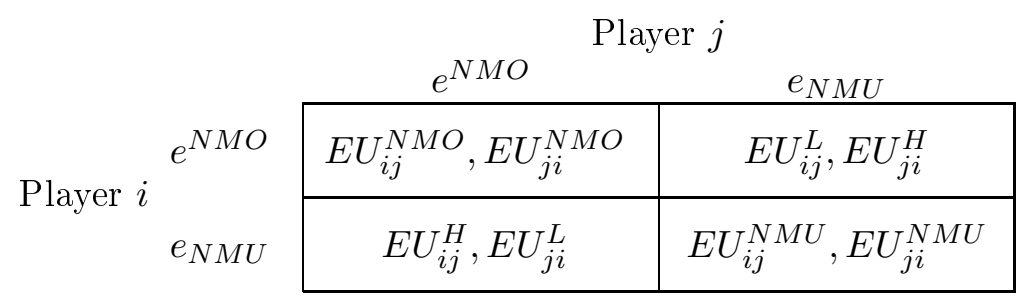

Figure 1: the non-market insurance game in strategic form

Once this game is put in a dynamic setting, the social network can be described as in Vega-Redondo (2006): we have a finite population of agents $N=\{1,2, \ldots, n\}$ where each pair of interacting agents $i, j$ is involved in an infinite repetition of the described game. Players' connecting decision is captured by a directed graph $\vec{g} \subset N \times N$, where each directed link $(i, j) \in \vec{g}$ is player $i$ decision to connect with player $j$. Suppose now that every linking decision lead to play. We have a definition for social network:

Definition 1 (Social Network) The social network induced by the linking decision $\vec{g}$ is the undirected graph $g \subset N \times N$ defined as

$$
\forall i, j \in N, \quad(i, j) \in g \Longleftrightarrow[(i, j) \in \vec{g} \vee(j, i) \in \vec{g}]
$$

and for any player $i$ the set of her neighbors is

$$
N_{i}=\{j \in N:(i, j) \in g\}
$$

In order to complete the repeated game model we need a rule for information diffusion within the network: in our model information spread around the network only gradually. To be specific, at each round before playing $i, j$ share information about their behavior with their neighbors, i.e. whether they deviated from the cooperative strategy. To sustain a cooperative equilibrium it's also necessary that each agent adopts a strategy that punish defiance: $i$ force herself to play a trigger strategy, i.e. she will switch to defection with $j$ as soon as she knows $j$ deviated with some of her neighbors. More formally, for any agent $i$ the strategy $s^{g}=\left(s_{1}^{g}, \ldots, s_{n}^{g}\right)$ is of the following type: 
1. first, player $i$ chooses whether to start her interaction with $j$ putting effort $e^{N M O}$ (which is to cooperate) or to put effort $e_{N M U}$;

2. in the following rounds, she reacts immediately to the news $j$ did not start with $e^{N M O}$ with some $k \in N_{j}$ switching irreversibly to $e_{N M U}$ in her game with $j$.

In order to give a definition of an equilibrium, some additional notation is needed: $\pi_{i}\left(s^{g}\right)$ is the overall payoff from the link $(i, j)$ given the strategy $s^{g}$; for every agent $i s_{C}^{g}$ and $s_{D}^{g}$ are the strategies that starts respectively with cooperation and defection with all the agents $k \in N_{i}$.

Definition 2 (Pairwise-stable Network (PSN)) a PSN is a network where for every separate link, the two players have incentives to sustain the cooperative equilibrium, i.e.

$$
\forall(i, j) \in g \quad \pi_{i}\left(s_{C}^{g}\right) \geq \pi_{i}\left(s_{D}^{g}\right)
$$

The connection of this definition with the Social Capital literature is clear once the PSN is characterized in terms of cohesiveness. Let define

Definition 3 (i-excluding distance) $d^{i}(j, k)$, the $i$-excluding distance between $j$ and $k$ is the shortest path joining $j$ and $k$ which does not involve player $i$. In other words, it is the number of steps needed for any information held by $j$ to reach $k$ (and vice versa) without the concourse of $i$.

Then

Proposition 4 Let $g$ be a Social Network where agents play the described game, and they all face a common discount factor $\eta \in(0,1)$. Define $\nu_{i k}=$ $E U_{i k}^{N M O}-E U_{i k}^{L}$ Then, $g$ is a PSN if and only if for all $(i, j) \in g$

$$
E U_{i j}^{N M O}+\sum_{k \in N_{i} /\{j\}} \eta^{d^{i}(j, k)}\left[\eta E U_{i k}^{N M O}+(1-\eta) \nu_{i k}\right] \geq(1-\delta) E U_{i j}^{H}
$$

Proof of proposition 1 is in the appendix and follows the one in VegaRedondo (2006). The implications of this proposition are:

- Stability is more likely in large span networks, i.e. in networks where each agent $i$ has a large neighborhood $N_{i}$;

- Stability is more likely in cohesive networks, i.e. in networks with small excluding distances $d^{i}(j, k)$.

It is also clear that, since payoffs are uncertain, the level of volatility in the model is inversely related with stability. Given this formalization, 
Definition 4 (Social Capital) The stock of Social Capital of the network $g$ is the density ${ }^{5}$ of $g$.

Going back to the first part of the model, we showed that demand for market insurance is affected by non-market insurance agreement if they do not involve moral hazard. In a pairwise stable network agents have no incentives to reduce the effort, i.e. moral hazard is inversely related to network stability. Therefore, from definition 4 the empirical implication of the model is that demand for market insurance depend on Social Capital. Further on, as Vega-Redondo pointed out cohesiveness is network counterpart of Coleman's concept of closure of a Social Network. We have a second empirical implication: demand for market insurance is related to network closure.

\section{Demographics and insurance data}

In order to identify the effect of social capital on insurance purchases, we have to control for the determinants of insurance development. Theoretical models of non-life insurance demand, starting from the seminal paper of Mossin (1968), predict that for a given level of risk exposure insurance demand is increasing with risk aversion, probability of loss and wealth at stake. Empirical studies identify some observable counterparts. Wealth, when not observable, is generally proxied by means of income or bank deposits; so it is risk exposure, which is in turn related to total wealth and the level of economic activity. Loss probability may too be related to income as a measure of economic activity; urbanization has also been suggested for this purpose (Browne et al. (2000)). Loss ratios ${ }^{6}$ have also been suggested as a proxy for the probability of loss. Aspects of risk aversion may be captured by education or the age structure of the population, even though the expected sign of the effect is unclear (see Browne and Kim (1993), Grace and Skipper (1991) and the discussion in Browne et al. (2000)).

\subsection{Controlling for supply side variables}

We stated in section 2 that an insurance company has a limited discriminating power, i.e. if individuals are heterogeneous it can offer different contracts (which means different prices) based on observable characteristics of individuals in a particular subpopulation, but it can't offer individual contracts based on effort, which is always unobserved by the insurer. This means that in an empirical investigation on demand for insurance it is crucial to control for supply side changes (i.e. for offered prices), in order to be sure that the marginal effects of interest (which we investigate based on the demand equation) are not completely absorbed by equilibrium prices. This is

\footnotetext{
${ }^{5}$ The density is the average number of links per agent (degree) in the network.

${ }^{6}$ Loss ratios are defined as the ratio of claims incurred to premiums earned.
} 
a non-trivial problem: as Schlesinger (in Dionne (2000)) notes, "it is often difficult to determine what is meant by the price and the quantity of insurance. $[. .$.$] the fundamental two building blocks of economic theory have no$ direct counterparts for insurance". In practice we can usually only observe insurance consumption, the product between equilibrium price and quantity, jointly determined by the interplay of supply and demand. The choice of a price variable, when available at all, is therefore far from being obvious. We cannot observe the amounts insured, therefore inclusion of medium premium rates, which would probably be best, is ruled out. We resort therefore to the loss ratio, as e.g. in Esho et al. (2001), observing that the role of this index as a proxy for market riskiness could lead to some ambiguity. Due to unavailability of data on losses for the non-life market as a whole, we include the aggregate loss ratio for the property sector only (Fire, Motor non-TPL, Other material loss).

Lastly, given the importance of tied agents in the distribution of insurance products (this channel did account in 2000 for 88.3 of non-life premium volume $)^{7}$, the number of agencies per capita has been included as a supply-side driver, inversely related to the opportunity-cost of searching for insurance covers.

Our dataset consists mainly of an excerpt for the years 1998-2000 from the Geo-Starter database provided by Istituto Tagliacarne, an institution inside SiStaN (the Italian national statistical system). It provides both first-hand data and an organized collection of data from various institutional sources. Data on insurance premiums, in particular, are collected on a provincial basis by ISVAP, the Italian insurance Authority, divided into three categories: life, compulsory third party liability, the vast majority of which regarding motor vehicles, and other non-life. While motor third party liability is a homogeneous class, both life and other non-life comprise very different kinds of policies.

\subsection{Measuring insurance consumption}

As noted above, we are only able to observe the equilibrium value of insurance consumption, and neither the quantity nor the price of insurance. Furthermore, measuring insurance consumption across administrative regions of different economic and demographic "size" requires resorting to some kind of relativization. Two common normalized measures are used in the literature as well as among practitioners: insurance penetration, defined as the ratio of insurance premiums on GDP, measures the importance of the insurance sector with respect to the total economy; insurance density, defined as premiums per capita, measures average per capita expenditure. We focus henceforth on premiums per capita. In the same fashion, all variables sub-

\footnotetext{
${ }^{7}$ Including motor TPL.
} 
ject to a size bias in the information set have been normalized with respect to the relevant benchmark.

\subsection{Locational issues}

Premium data are registered according to the location of sales point as communicated by the companies. Besides the inevitable aggregation bias due to the arbitrarinesses of administrative boundaries with respect to the geographic dimension of economic phenomena (see Anselin (1988)), some important additional biases may arise if the location of sales point is different from the actual location of the insured.

First, mostly for big contracts negotiated by brokers but also for some distribution agreements, e.g., in bancassurance, some big units, usually located in an important industrial or financial center, are accountable for all business nationwide. This happens, for example, for marine insurance premiums collected by business units located in the main harbours for customers located and doing business elsewhere, or for some nationwide salesmen network whose business goes through a single agency, typically located at the company headquarters.

Second, collective policies purchased by the firms as a mandatory cover or as a fringe benefit for their employees, most typically in the accident, health and life classes, are bound to one sales point location even if they are actually insuring risks spread over a wider territory.

\subsection{Administrative boundaries in Italy}

In the following, we refer to the Italian administrative units called province, corresponding to level 3 in the NUTS (Nomenclature of Territorial Units for Statistics) classification by Eurostat, using the generic name of regions, and to the classification used by Istat, the Italian statistical office, when speaking of macro-regions. Macro-regions divide the 20 NUTS2 Italian regions (regioni) into 5 aggregates: North-West, North-East, Centre, South and Islands.

\section{How to measure Social Capital?}

In the third section we tackled one of the major problems pointed out by Durlauf and Fafchamps (2004), which is to give a sound economic meaning to Social Capital. Now we have to address a second controversial issue: a reasonable empirical measure of this sociological concept.

Our definition suggests a somewhat natural way to measure Social Capital effect: as we stated in the previous section, what matters is social capital endowment and closure of Social Networks. Since we have province level data, we want to measure the density and cohesiveness of social networks 
characterizing each province. We are not the first to try to measure closure with this kind of data: Goldin and Katz (1998) based their empirical measure of Social Capital intensity directly on Coleman's definition of closure. They have a dataset on schooling and some economic variables on Iowa, USA in 1915. The detail is at county level, comparable to Italian provinces. Their measure was the proportion of county population living in small towns. Their claim was that

Small town in America was a locus of associations (religious, fraternal/sororal, business, and political organizations) that could have played an important role in galvanizing support for the provision of local publicly provided goods [...]. These associations $[\ldots]$ provide another indicator of community cohesion.

As they did, we want to measure closure of social networks with the dimension and isolation of communities. Goldin and Katz's measure can be replicated for our data, but it's not sufficient to identify isolated communities: in 1915 Iowa the overall population density was very low, therefore living in a small village meant at the same time living kilometers far away from other towns. Nowadays Italy on the contrary is characterized by a very high population density. This means that living in a small town doesn't necessarily mean living in an isolated place. An example is the Po valley in northern Italy: towns can be really small, below 1000 inhabitants, but they often happen to be one beside another with no free land in the middle. This means that the percentage of population living in small towns alone does not necessarily identify isolated communities. Therefore, our claim is that the degree of closure of social networks characterizing an Italian province is identified by the percentage of population living in towns with less than 1000 citizens (pupop1000), but also by other three variables. The first two are the fraction of province's hill territory (percsup.c) and the fraction of mountainous territory (percsup.m), which should control for 'Po valley' effect. The third variable controls for a different potential source of cohesiveness: a province where people are mainly involved in agriculture could be expected to be a closed community (in the Coleman sense), either for cultural reasons or for common working interests. Such an effect is captured by the fraction of territory devoted to agriculture (percsup.agr), which in this context seems more meaningful and coherent with our definition of social capital than the pure Goldin and Katz measure. Those variables seems to be informative, i.e. they do not simply follow a North-South gradient: 


\begin{tabular}{|c|c|c|c|c|c|c|}
\hline pupop1000 & Min. & 1st Qu. & Median & Mean & 3rd Qu. & Max. \\
\hline North West & 0.3158 & 0.5512 & 0.7080 & 0.6492 & 0.7805 & 0.8443 \\
\hline North East & 0 & 0.1183 & 0.4085 & 1.6490 & 2.0880 & 13.780 \\
\hline Centre & 0 & 0.4006 & 0.7385 & 1.6300 & 1.6120 & 14.430 \\
\hline South & 0 & 0 & 1.936 & 2.901 & 2.612 & 20.520 \\
\hline Islands & 0 & 0 & 0.2445 & 2.0190 & 1.9270 & 12.670 \\
\hline percsup.m & Min. & 1 st Qu. & Median & Mean & 3rd Qu. & Max. \\
\hline North West & 0 & 9.078 & 44.960 & 43.180 & 64.310 & 100 \\
\hline North East & 0 & 0 & 24.540 & 29.170 & 40.200 & 100 \\
\hline Centre & 0 & 7.080 & 31.680 & 31.020 & 42.480 & 85.320 \\
\hline South & 0 & 3.990 & 29.730 & 32.120 & 54.200 & 100 \\
\hline Islands & 0 & 0 & 11.100 & 16.860 & 30.680 & 66.300 \\
\hline percsup.c & Min. & 1st Qu. & Median & Mean & 3rd Qu. & Max. \\
\hline North West & 0 & 6.503 & 18.700 & 25.240 & 38.250 & 97.290 \\
\hline North East & 0 & 0 & 20.380 & 23.120 & 35.910 & 100 \\
\hline Centre & 0 & 47.310 & 65.500 & 60.580 & 74.140 & 100 \\
\hline South & 0 & 32.100 & 52.950 & 47.590 & 60.980 & 80.910 \\
\hline Islands & 33.700 & 53.520 & 65.200 & 64.610 & 73.880 & 86.970 \\
\hline percsup.agr & Min. & 1st Qu. & Median & Mean & 3rd Qu. & Max. \\
\hline North West & 0.0684 & 0.1911 & 0.3766 & 0.4254 & 0.6884 & 0.9101 \\
\hline North East & 0.1173 & 0.4370 & 0.6626 & 0.5735 & 0.7328 & 0.8843 \\
\hline Centre & 0.1717 & 0.4133 & 0.5166 & 0.5035 & 0.6147 & 0.7603 \\
\hline South & 0.2202 & 0.5632 & 0.6638 & 0.6372 & 0.7545 & 0.9197 \\
\hline Islands & 0.3158 & 0.5512 & 0.7080 & 0.6492 & 0.7805 & 0.8443 \\
\hline
\end{tabular}

The network definition we use for Social Capital is a local interaction concept: the social network is based on direct links among individuals and therefore quite probably on geographic proximity.

Moral hazard may well depend also on global interaction effects. To be specific, it may depend on a trust feeling towards others by individual not necessarely induce by direct linking, but based on general experience, prejudice, culture and so on. If global interactions have a role in explaining moral hazard and therefore insurance demand, a measure of them must be included among the regressors in order to have an unbiased estimate of local social interaction effects, since global and local interactions are likely to be correlated. To measure global interaction, we follow Guiso et al. (2004) using an index derived from a question in the "World Value Survey", run in Italy in 1999. The question asked was

"Using the responses of this card, could you tell me how much you trust other Italians in general? (5) Trust them completely, 
Figure 2: geographical distribution of pupop1000 and agricultural land pupop1000 percsup.agr
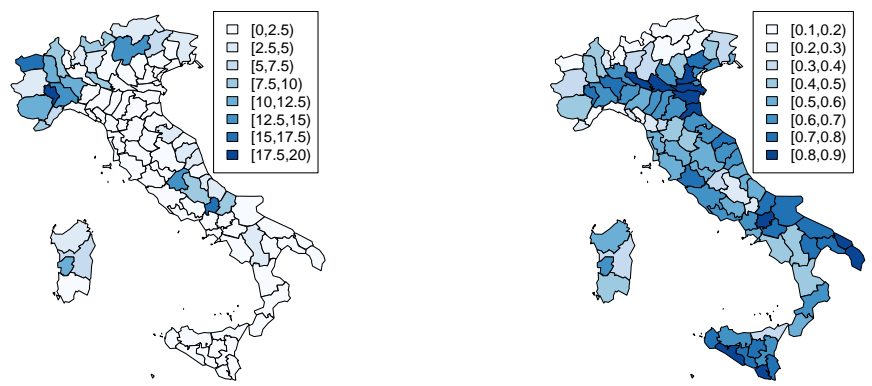

Figure 3: geographical distribution of mountainous and hill territory percsup.m percsup.c
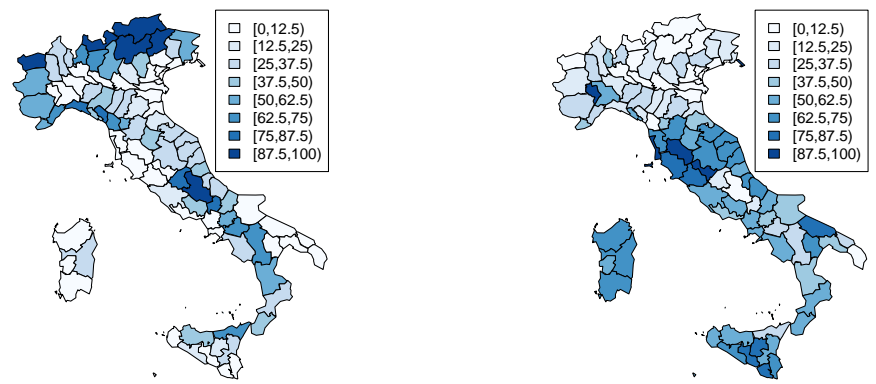
(4) Trust them a little, (3) Neither trust them, nor distrust, (2)

Do not trust them very much, (1) Do not trust them at all"

The answers to the "World Value Survey" are published aggregated at regional level. This could generate a potential collinearity problem with the macro-areas dummies, nevertheless Trust index values don't seem to follow exactly a north-south gradient:

\begin{tabular}{lrrrrrr}
\hline trust & Min. & 1st Qu. & Median & Mean & 3rd Qu. & Max. \\
\hline North West & 3.172 & 3.313 & 3.313 & 3.316 & 3.371 & 3.371 \\
North East & 3.132 & 3.22 & 3.352 & 3.302 & 3.386 & 3.398 \\
Centre & 3.068 & 3.11 & 3.185 & 3.239 & 3.351 & 3.351 \\
South & 3.029 & 3.091 & 3.244 & 3.201 & 3.247 & 3.625 \\
Islands & 3.172 & 3.172 & 3.172 & 3.191 & 3.236 & 3.236 \\
\hline
\end{tabular}

Figure 4: geographical distribution of Trust

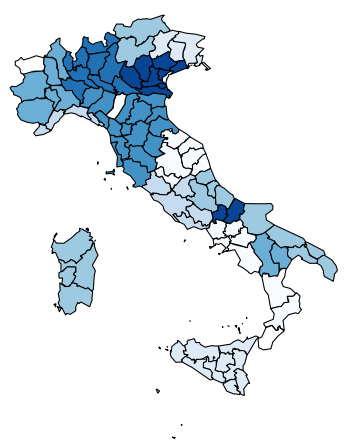

\section{$6 \quad$ Model estimation and results}

Our dataset is a balanced panel: we have 103 observations (one for each province) observed over three years, from 1998 to 2000. A pooled OLS is likely to be inefficient, since the IID hypothesis on the error terms is usually inappropriate in panel data settings. Once the longitudinal dimension of the dataset is taken into account, such a hypothesis can be tested. If the poolability test rejects, the choice remains open between a fixed effects (FE) and a random effects (RE) specification. In our case we are forced to choose RE: 
FE estimators are based on within-group heterogeneity, i.e. they require all the explanatory variables to vary within each group (in our case, within each province). Two of our key explanatory variables are based on the shape of a province's territory, which is clearly invariant. Even excluding these regressors, many other variables have a low variability across years and within each province $^{8}$, which would reduce the efficiency of a FE estimator.

\subsection{The panel model}

The econometric model to be estimated in its most general form is the following error components model:

$$
y_{i t}=\boldsymbol{X}_{i t} \boldsymbol{\beta}+\nu_{i}+\epsilon_{i t} \quad i=1, \ldots, 103 ; t=0, \ldots, 2
$$

where $\boldsymbol{X}, \nu_{i}$ and $\epsilon_{i t}$ are independent of each other and both uncorrelated with the explanatory variables. $y_{i t}$ is the log of non-life insurance premiums per capita in province $i$ in year $1998+t$.

Defining $\xi_{i t}=\nu_{i}+\epsilon_{i t}$, the assumption that shocks are independent can be rewritten as

$$
\begin{aligned}
\operatorname{Var}\left(\xi_{i t}\right) & =\sigma_{\nu}^{2}+\sigma_{\epsilon}^{2} & & \\
\operatorname{Cov}\left(\xi_{i t}, \xi_{i s}\right) & =\sigma_{\nu}^{2} & & \forall t \neq s \\
\operatorname{Cov}\left(\xi_{i t}, \xi_{j s}\right) & =0 & & \forall t \neq s, i \neq j
\end{aligned}
$$

A test for the RE model against a pooled OLS is a test for

$$
\begin{aligned}
& H_{0}: \sigma_{\nu}^{2}=0 \\
& H_{1}: \sigma_{\nu}^{2}>0
\end{aligned}
$$

Assuming normality of the errors, a parsimonious testing strategy can be based on the Lagrange Multiplier principle: the OLS model is estimated and then maintained, while it is compared to the more general alternative in a maximum likelihood framework. Test statistics are based on the OLS residuals without need to estimate the panel model. Baltagi (1995) reports the original LM test derived by Breusch and Pagan together with some refinements. We run the King and Wu modification, which is distributed as a standard normal ${ }^{9}$. The result of the test is 0.8895 , with $\mathrm{p}$-value equal to 0.1869 , thus not providing any evidence in favor of the random effects model.

Relaxing the assumption of "well behaved" residuals (see (9) and (10) below), another test for the RE hypothesis feasible in short panels is given in Wooldridge (2002). This is based on estimation of $\sigma_{\nu}^{2}$ from the upper

\footnotetext{
${ }^{8}$ See the summary table in the appendix.

${ }^{9}$ This is a locally mean most powerful refinement of the usual Breusch-Pagan $\chi^{2}$ test. Breusch and Pagan test $H_{0}: \sigma_{\nu}^{2}=0$ against $H_{1}: \sigma_{\nu}^{2} \neq 0$, thus rejecting for $\sigma_{\nu}^{2}<0$, which should be excluded by the model restrictions. The original Breusch and Pagan test strongly rejects the null.
} 
triangle of the $N$ empirical $\Omega$ blocks given by the outer product of the residuals vectors $\tilde{v}_{i}=\left(\tilde{v}_{i 1}, \ldots, \tilde{v}_{i T}\right)$. The result of the test is 5.4713 , with p-value smaller than $10^{-7}$, this time favoring the random effects model. As RE estimators remain consistent under the OLS specification, we proceed estimating an RE model.

\subsection{The random effects model}

Under the RE specification, homoskedasticity in both $\nu_{i}$ and $\epsilon_{i t}$ and no serial correlation in $\epsilon_{i t}$, the variance-covariance matrix of the errors becomes

$$
V=\sigma_{\nu}^{2}\left(I_{N} \otimes \boldsymbol{i}_{T} \boldsymbol{i}_{T}^{\prime}\right)+\sigma_{\epsilon}^{2}\left(I_{N} \otimes I_{T}\right)
$$

where $I_{N}$ is the $N \times N$ identity matrix and $\boldsymbol{i}_{N}$ is a $N \times 1$ vector of 1 . Therefore, $V$ is block-diagonal with

$$
V=I_{N} \otimes \Omega
$$

where

$$
\Omega=\left[\begin{array}{cccc}
\sigma_{\epsilon}^{2}+\sigma_{\nu}^{2} & \sigma_{\nu}^{2} & \cdots & \sigma_{\nu}^{2} \\
\sigma_{\nu}^{2} & \sigma_{\epsilon}^{2}+\sigma_{\nu}^{2} & \cdots & \vdots \\
\cdots & & \ddots & \sigma_{\nu}^{2} \\
\sigma_{\nu}^{2} & & & \sigma_{\epsilon}^{2}+\sigma_{\nu}^{2}
\end{array}\right]
$$

Observations regarding the same province share the same $\nu_{i}$ effect, thus the relative errors are autocorrelated, with $\operatorname{Corr}\left(v_{i s} v_{i t}\right)=\frac{\sigma_{\nu}^{2}}{\left(\sigma_{\epsilon}^{2}+\sigma_{\nu}^{2}\right)}$. Ordinary least squares estimates for $\beta$ in model (7) are therefore inefficient, though consistent. Generalized least squares (GLS) are the efficient solution if $\Omega$ is known. Various feasible GLS procedures exist drawing on consistent estimators of $\Omega$.

The standard approach to RE panels is to assume both (9) and (10). In "large N" panels a less restrictive approach is possible, termed general FGLS estimator (GGLS) Wooldridge (2002), which allows for arbitrary intra-group heteroskedasticity and serial correlation of errors, i.e. inside the $\Omega$ covariance blocks, provided that these remain the same for every individual. For the sake of robustness, we try out both estimators. Results are much alike; GGLS are reported in the appendix.

\section{Spatial structure}

As observed while describing insurance data, there are good reasons to think that non-life insurance activity may not follow provincial administrative boundaries. For example, the latter may overlap with operational areas of the sales force, or there may be any other kind of cross-border purchase. As 
in many other studies about the spatial distribution of an economic phenomenon, this problem cannot be neglected. In particular, Millo and Lenzi (2005) found evidence of spatial correlation for several specifications of regressions of insurance on a set of demographics, based on the very same dataset.

In econometric applications, proximity between data points in space is usually characterized by means of a proximity matrix, say, $W$, containing a measure of proximity for every pair of data points and, by convention, setting the diagonal to zero. Hence a spatial lag operator is defined such that $W y$, the spatial lag of $y$, stands for "the values of $y$ at neighboring locations"10. Anselin (1988) warns about the relevant consequences on estimation (and, to a lesser extent, on testing) of the choice of $W$. Here we resorted to a proximity matrix where each entry $w_{i j}$ is the inverse of coordinates' distance between province $i$ and $j$, with a cut-off point at $250 \mathrm{~km}$ (i.e., any $w_{i j}<1 / 250$ is set equal to 0 ). This has been row-standardized, so that the spatial lag of $y, W y$, is simply the weighted average of values of $y$ at neighboring locations.

The two standard specifications for spatial effects in regression models are the spatial lag (SAR) model:

$$
y=\rho W y+X \beta+\epsilon
$$

and the spatial error (SEM) model:

$$
\begin{aligned}
& y=X \beta+e \\
& e=\lambda W e+\epsilon
\end{aligned}
$$

The consequences on estimation of omitting the lagged dependent variable are inconsistency and biasness of parameter estimates. Neglecting a spatial error structure has less serious consequences: estimates, while still consistent, are inefficient. Therefore, we concentrated our analysis on a SAR extension of our panel random effects model. Following Elhorst (2001), stacking the data as one cross section for every point in time and assuming $\epsilon \sim I I D$, the panel RE version of (11) becomes

$$
y=\rho\left(I_{T} \otimes W\right) y+X \beta+\left(i_{T} \otimes \nu\right)+\epsilon
$$

where the variance covariance matrix of $\left(i_{T} \otimes \nu\right)+\epsilon$ is a block matrix where each block corresponds to a point in time $t$ and has the same structure as $V$ defined in the previous section. Results are reported in Table 1.

Social Capital effects are not completely absorbed by equilibrium prices: supply side proxies (in particular $\log (a g / p o p)$ ) do have a positive effect but three out of four Social Capital proxies have positive and significant coefficients' estimates. Trust is positive and significant as well, confirming the role of global interactions. About spatial structure, as we expected non-life

\footnotetext{
${ }^{10}$ See Anselin (1988), Ch.3, for a classic treatment.
} 
Table 1: panel RE spatial autoregressive model estimates

\begin{tabular}{rrrrr}
\hline & coef & $\mathrm{se}$ & $\mathrm{z}$ & $\mathrm{pz}$ \\
\hline $\log$ (Ydproc) & 1.1881 & 0.1726 & 6.8852 & 0.0000 \\
$\log$ (dep/pop) & 0.0780 & 0.0482 & 1.6186 & 0.1055 \\
$\mathrm{I}$ (pop25.54/popover60) & 0.2101 & 0.1225 & 1.7148 & 0.0864 \\
$\mathrm{I}(\mathrm{va} / 1000)$ & 0.0033 & 0.0013 & 2.5465 & 0.0109 \\
$\mathrm{u}$ & -0.0006 & 0.0018 & -0.3628 & 0.7168 \\
qexport & 0.0517 & 0.0818 & 0.6311 & 0.5279 \\
$\mathrm{I}($ va.serv/va) & 0.3525 & 0.4452 & 0.7917 & 0.4285 \\
$\mathrm{I}$ (va.indutot/va) & 0.4285 & 0.4462 & 0.9604 & 0.3368 \\
$\mathrm{I}($ den/1000) & 0.1037 & 0.0568 & 1.8264 & 0.0678 \\
numcompfam & 0.0335 & 0.1082 & 0.3098 & 0.7567 \\
lrpro & 0.0157 & 0.0212 & 0.7379 & 0.4606 \\
$\log$ (ag/pop) & 0.1238 & 0.0500 & 2.4743 & 0.0134 \\
inef & -0.0509 & 0.0129 & -3.9396 & 0.0001 \\
dum98 & -0.0718 & 0.0116 & -6.2073 & 0.0000 \\
dum99 & -0.0226 & 0.0091 & -2.4876 & 0.0129 \\
NO & 0.0534 & 0.0601 & 0.8889 & 0.3741 \\
NE & 0.0917 & 0.0539 & 1.7009 & 0.0890 \\
SU & -0.2414 & 0.0606 & -3.9818 & 0.0001 \\
$\mathrm{IS}$ & -0.2606 & 0.0711 & -3.6650 & 0.0002 \\
trust & 0.4787 & 0.1397 & 3.4257 & 0.0006 \\
pupop1000 & 0.1165 & 0.0371 & 3.1360 & 0.0017 \\
percsup.m & 0.0027 & 0.0012 & 2.2276 & 0.0259 \\
percsup.c & 0.0009 & 0.0009 & 1.0260 & 0.3049 \\
percsup.agr & 0.0727 & 0.1469 & 0.4950 & 0.6206 \\
pupop1000:percsup.agr & -0.0909 & 0.0398 & -2.2827 & 0.0224 \\
rho & 0.0908 & 0.0293 & 3.0979 & 0.0019 \\
\hline pupop1000:percsup.m & -0.0012 & 0.0003 & -3.5274 & 0.0004 \\
& & & &
\end{tabular}


insurance demand exhibits spatial correlation: $\rho$ is positive and significant. Significance of the interaction parameters suggests for a non-linear dependence on our Social Capital proxies. Therefore we computed marginal effects for Social Capital variables. ${ }^{11}$.

\begin{tabular}{rrrrr}
\hline & eff.marg. & se & t-ratio & p-value \\
\hline pupop1000 & 0.0086 & 0.0041 & 2.0802 & 0.0384 \\
percsup.m & -0.0010 & 0.0010 & -1.0164 & 0.3103 \\
percsup.c & -0.0007 & 0.0007 & -0.9369 & 0.3496 \\
percsup.agr & -0.2181 & 0.1227 & -1.7766 & 0.0767 \\
\hline
\end{tabular}

Marginal effect of pupop1000, which was the only one interacted with all the other Social Capital variables, is positive and significant, even if reduced in magnitude. Given these results, we investigated the relation between Social Capital and spatial correlation in the dependent variable.

\subsection{Social Capital and spatial effects}

As for non-life insurance demand, Social Capital may not follow administrative boundaries and may exhibit a spatial structure. A first evidence in this direction comes from the moran plots of non-life insurance and the social capital variables we chose (see figure 5).

Moran's I statistic is a spatial correlation measure. In this case the proximity matrix is a row-standardized dichotomic matrix: Moran's I statistic thus boils down to the regression coefficient of the variable of interest over its spatial lag (see Anselin (1988)). The Moran plot is the relative scatter plot, where on the $\mathrm{x}$-axis there is the variable of interest and on the $\mathrm{y}$-axis its spatial lag. The straight line is the OLS estimated one. Therefore graphs show that both the variable of interest ( $\mathrm{ppcd}$, which are log premium per capita) and the social capital variables exhibit spatial correlation. Moran's I statistics gives the same indication if a distance-based $W$ is used. What we expected than is that since the empirical implication of our model is a causal relation between Social Capital and insurance demand, such a causality should reflect in the spatial structure as well.

To test it, we repeated the panel SAR estimation for a model which do not include Social Capital variables, and compared the magnitude of the spatial correlation coefficient:

\begin{tabular}{l|rrrc} 
& coef & se & z-stat & p-value \\
\hline$\rho$ w/o Soc. Cap & 0.1730 & 0.0314 & 5.5138 & $<10^{-4}$ \\
$\rho$ with Soc. Cap & 0.0908 & 0.0293 & 3.0979 & 0.0019
\end{tabular}

\footnotetext{
${ }^{11}$ Marginal effects are computed over the mean of the relevant variable.
} 
Figure 5: Moran plots

ppcd

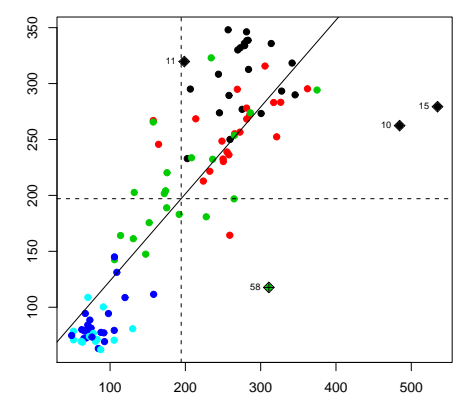

percsup.c

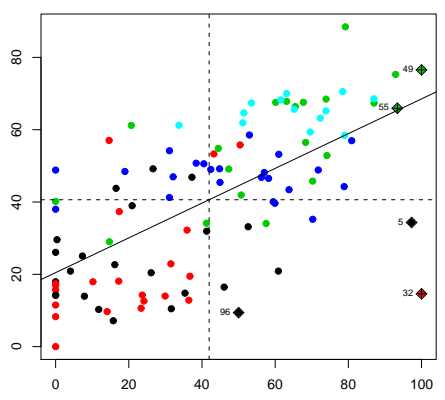

percsup.agr

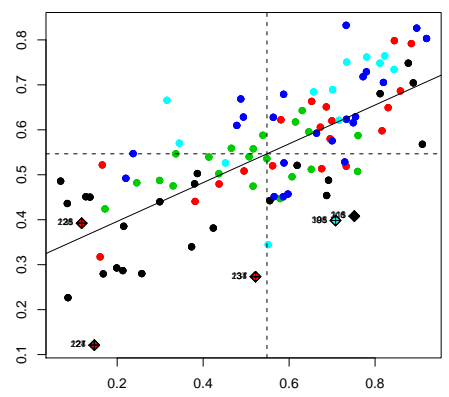

pupop1000
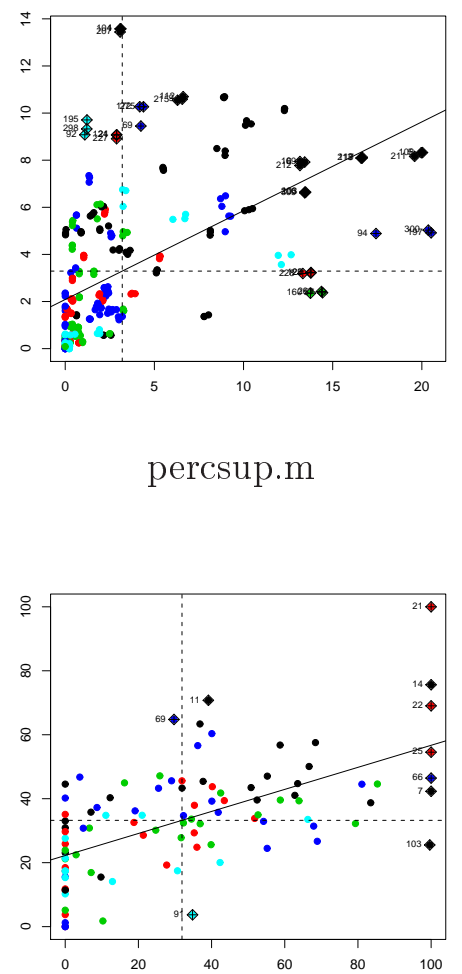

Colors' legend:

- black $=$ North-West

- red = North-East

- green $=$ Center

- blue = South

- light blue = Islands 
Results of these tests are in line with the causal relation implied by the model: a panel model without social interactions effects exhibits a significant Spatial autocorrelation structure $(\rho \neq 0)$. Augmenting the model with social capital variables almost halves the spatial correlation coefficient, meaning that Social Capital has a positive marginal effect on non-life insurance demand, and its spatial structure accounts for a large part of insurance demand's spatial structure.

\subsection{Robustness checks}

Anselin (1988) points out the possible bias introduced by a wrong choice of the proximity matrix $W$. We performed a robustness check employing one binary contiguity matrix ${ }^{12}$ and two different distance-based matrices: the first based on the inverse of road travelling distance, the second on the inverse of the euclidean distance between the geographic coordinates of capital cities in each province. The results of the two alternative distance-based specifications are much alike given the same cut-off point, as they are choosing different cut-off points:

Table 2: $\rho$ coefficient by cutoff point

\begin{tabular}{rrrrr}
\hline KM & coef & se & $\mathrm{z}$ & $\mathrm{pZ}$ \\
\hline 50 & 0.0657 & 0.0201 & 3.2670 & 0.0011 \\
75 & 0.0903 & 0.0205 & 4.3981 & 0.0000 \\
100 & 0.1036 & 0.0214 & 4.8310 & 0.0000 \\
125 & 0.1128 & 0.0224 & 5.0254 & 0.0000 \\
150 & 0.1194 & 0.0233 & 5.1199 & 0.0000 \\
175 & 0.1286 & 0.0246 & 5.2193 & 0.0000 \\
200 & 0.1112 & 0.0262 & 4.2418 & 0.0000 \\
225 & 0.0937 & 0.0278 & 3.3760 & 0.0007 \\
250 & 0.0908 & 0.0293 & 3.0979 & 0.0019 \\
\hline
\end{tabular}

Once the model is estimated with the $0 / 1$ matrix there is no evidence of spatial dependence regardless of the presence or not of the Social Capital variables ${ }^{13}$. Nevertheless given the problem at hand such a proximity matrix seems to us less reasonable than a distance based one: provinces' extensions varies a lot, and so do travelling costs and Social Capital: a 0/1 matrix do not accounts for such an heterogeneity.

A SAR model gives consistent estimates, but if there is unexplained spatial correlation in the error term these estimates may not be efficient. To account for that we would need a sort of spatial ARMA model, accounting

\footnotetext{
${ }^{12} \mathrm{~A}$ binary contiguity matrix is a $0 / 1$ matrix where $w_{i j}=1$ if $i$ and $j$ share a common boundary, 0 otherwise.

${ }^{13}$ results are not reported but are available upon request
} 
both for the autoregressive spatial component and the spatial error one. In our case we would need a panel version of such a model, which is still an open issue in the spatial econometric literature. Therefore, as a first test we estimated a panel SEM (spatial error model) without the autoregressive component. Elhorst (2001) suggests the following specification:

$$
\begin{gathered}
y=X \beta+\left(i_{T} \otimes \mu\right)+e \\
e=\lambda\left(I_{T} \otimes W\right) e+\epsilon
\end{gathered}
$$

We report estimates of $\lambda$ with proximity matrices with different cut-offs:

Table 3: $\lambda$ coefficient by cutoff point

\begin{tabular}{rrrrr}
\hline KM & coef & se & z & pz \\
\hline 50 & -0.1966 & 0.1323 & -1.4858 & 0.1373 \\
75 & -0.2188 & 0.1682 & -1.3011 & 0.1932 \\
100 & -0.2907 & 0.2198 & -1.3224 & 0.1860 \\
125 & -0.3650 & 0.2637 & -1.3842 & 0.1663 \\
150 & -0.4398 & 0.2936 & -1.4982 & 0.1341 \\
175 & -0.4626 & 0.3172 & -1.4584 & 0.1447 \\
200 & -0.4956 & 0.3403 & -1.4563 & 0.1453 \\
225 & -0.5312 & 0.3545 & -1.4982 & 0.1341 \\
250 & -0.5358 & 0.3690 & -1.4520 & 0.1465 \\
\hline
\end{tabular}

$\lambda$ is never significant, thous providing evidence in favour of efficiency of the SAR specification we chose.

\section{Conclusions}

We started from Arnott and Stiglitz model on the co-existence of marketed and non-marketed insurance contracts, concentrating on implications on the demand function. We extended tghe model to allow for Social Capital as a potential explanatory variable. We chose a network approach: non-market agreement are described as strategic decisions of agents playing a prisoners' dilemma type of game with their neighbors. Each of them adopt a trigger strategy to punish neighbors deviating from the cooperative equilibrium in any game they are involved. Such a behavior lead to a Pairwise Stable Equilibrium which is more likely the higher the level of Social Capital embedded in the Social Network. Here comes the first contribution of our paper: the network approach we chose provide us with a formal definition of Social Capital, which is crucial to obtain a clear testable model. The empirical part is carried out on a province-level Italian dataset provided by Istituto Tagliacarne. We carefully built 4 proxies for Social Capital and controlled for 
global interactions effect. We estimated a Spatial autoregressive RE panel model, and our testable implication, which was of a positive marginal effect for Social Capital on demand for market non-life insurance, is confirmed. Further on, we are able to explain a large part of the spatial correlation found by Lenzi and Millo on the very same dataset by means of the spatial structure of our new explanatory variables.

\section{References}

Anselin, L. (1988). Spatial Econometrics: Methods and Models. University of California, Santa Barbara: Kluwer Academic Publisher.

Arnott, R. and J. E. Stiglitz (1988). The basic analytics of moral hazard. The Scandinavian Journal of Economics $90(3), 383-413$.

Arnott, R. and J. E. Stiglitz (1991, March). Moral hazard and nonmarket institutions: Dysfunctional crowding out or peer monitoring? The American Economic Review 81(1), 179-190.

Baltagi, B. H. (1995). Econometric Analysis of Panel Data. UK: John Wiley \& Sons.

Browne, M., J. Chung, and E. Frees (2000). International property-liability insurance consumption. The Journal of Risk and Insurance $67, N^{\circ} 1$.

Browne, M. and K. Kim (1993). An international analysis of life insurance demand. The Journal of Risk and Insurance 60, 617-634.

Dionne, G. (2000). Handbook of Insurance. Dordrecht Netherlands: Kluwer Academic Publishers.

Durlauf, S. N. and M. Fafchamps (2004, July). Social capital. NBER Working Paper series.

Elhorst, J. P. (2001). Panel data models extended to spatial error autocorrelation or a spatially lagged dependent variable. Technical report, University of Groningen.

Esho, N., R. Zurbruegg, A. Kirievsky, and D. Ward (2001, June). Law and the determinants of property-casualty insurance. Technical report, Australian Prudential Regulation Authority.

Goldin, C. and L. F. Katz (1998, March). Human capital and social capital: the rise of secondary schooling in america, 1910 to 1940. NBER working paper series (6439). 
Grace, M. and H. Skipper (1991). An analysis of the demand and supply determinants for non-life insurance internationally. Technical report, CRMIR, Georgia State University.

Guiso, L., P. Sapienza, and L. Zingales (2004, June). The role of social capital in financial development. American Economic Review 94(3), 526-556.

Millo, G. and A. Lenzi (2005). Regional heterogeneity and spatial sillovers in the italian insurance market. Assicurazioni Generali Research Dept. Working Paper series 1.

Mossin, J. (1968). Aspects of rational insurance purchasing. Journal of Political Economy 79, 553-568.

Vega-Redondo, F. (2006). Building up social capital in a changing world. Journal of Economic Dynamics 63 Control 30, 2305-2338.

Wooldridge, J. (2002). Econometric analysis of cross-section and panel data. MIT Press. 


\section{A Proof of proposition 1}

The normalized payoff functions in case $i$ cooperates with $j$ is

$$
\begin{aligned}
\pi_{i}\left(s_{C}^{g}\right) & =\sum_{k \in N_{i}}\left\{(1-\eta) \sum_{\tau=0}^{\infty} \eta^{\tau} E U_{i j}^{N M O}\right\} \\
& =\sum_{k \in N_{i}} E U_{i j}^{N M O}
\end{aligned}
$$

while if $i$ deviates her anticipated payoff is

$$
\begin{aligned}
\pi_{i}\left(s_{D}^{g}\right)= & (1-\eta) E U_{i j}^{H}+\sum_{k \in N_{i} /\{j\}}\left\{\left[\sum_{s=0}^{d^{i}(j, k)-1}(1-\eta) \delta^{s} E U_{i k}^{N M O}\right]+(1-\eta) \delta^{d^{i}(j, k)} E U_{i k}^{L}\right\} \\
= & (1-\eta) E U_{i j}^{H}+\sum_{k \in N_{i} /\{j\}}\left\{\left[\sum_{s=0}^{d^{i}(j, k)-1}(1-\eta) \eta^{s} E U_{i k}^{N M O}\right]+(1-\eta) \eta^{d^{i}(j, k)} E U_{i k}^{N M O}\right. \\
& \left.-(1-\eta) \eta^{d^{i}(j, k)} \nu_{i k}\right\} \\
= & (1-\eta) E U_{i j}^{H}+\sum_{k \in N_{i} /\{j\}}\left\{\left(1-\eta^{d^{i}(j, k)+1}\right) E U_{i k}^{N M O}-(1-\eta) \eta^{d^{i}(j, k)} \nu_{i k}\right\}
\end{aligned}
$$

Therefore, the stability condition

$$
\pi_{i}\left(s_{C}^{g}\right) \geq \pi_{i}\left(s_{D}^{g}\right)
$$

Can be rewritten as

$$
\begin{aligned}
& \sum_{k \in N_{i}} E U_{i j}^{N M O} \geq(1-\eta) E U_{i j}^{H}+\sum_{k \in N_{i} /\{j\}}\left\{\left(1-\eta^{d^{i}(j, k)+1}\right) E U_{i k}^{N M O}-(1-\eta) \delta^{d^{i}(j, k)} \nu_{i k}\right\} \\
& E U_{i j}^{N M O}+\sum_{k \in N_{i} /\{j\}}\left(1-1+\eta^{d^{i}(j, k)+1}\right) E U_{i k}^{N M O} \geq(1-\eta)\left[E U_{i j}^{H}-\sum_{k \in N_{i} /\{j\}} \eta^{d^{i}(j, k)} \nu_{i k}\right] \\
& E U_{i j}^{N M O}+\sum_{k \in N_{i} /\{j\}}\left\{\eta^{d^{i}(j, k)+1} E U_{i k}^{N M O}+(1-\eta) \delta^{d^{i}(j, k)} \nu_{i k}\right\} \geq(1-\eta) E U_{i j}^{H} \\
& E U_{i j}^{N M O}+\sum_{k \in N_{i} /\{j\}} \eta^{d^{i}(j, k)\left[\eta E U_{i k}^{N M O}+(1-\eta) \nu_{i k}\right] \geq(1-\eta) E U_{i j}^{H}}
\end{aligned}
$$

Which is in the form of proposition 1. 


\section{B Variables' description and descriptive statistics}

Ydproc disposable income per capita

pop25.54/popover60 ratio of people aged 25-54 to people aged over 60

inef indicator of juridical system inefficiency: average duration of civil trials

den/1000 population density, inh. per sq. Km (scaled by a factor of 1000)

va.indutot/va share of industry on value added

va.serv/va share of services on value added

u unemployment rate

qexport share of export on total value added

numcompfam average number of family members

lrpro loss ratio of the property sector

trust trust indicator as defined by the World Values Survey (see above)

pupop500 share of population living in towns with less than 500 inhabitants

percsup.m share of mountainous territory

percsup.c share of hill territory

percsup.agr share of the land devoted to agriculture

dep/pop bank deposits per capita

va/1000 total value added (scaled by a factor of 1000)

ag/pop ratio of number of agencies over province's population

A table with some descriptive statistics follows. 


\begin{tabular}{rrrrrrr}
\hline & Min. & 1st Qu. & Median & Mean & 3rd Qu. & Max. \\
\hline $\log$ (Ydproc) & 9.00 & 9.27 & 9.54 & 9.47 & 9.63 & 9.84 \\
$\mathrm{I}$ (pop25.54/popover60) & 0.74 & 0.90 & 1.02 & 1.04 & 1.16 & 1.58 \\
inef & 1.44 & 2.74 & 3.47 & 3.79 & 4.59 & 8.32 \\
$\mathrm{I}($ den/1000) & 0.04 & 0.10 & 0.17 & 0.24 & 0.26 & 2.66 \\
$\mathrm{I}($ va.indutot/va) & 0.11 & 0.21 & 0.28 & 0.28 & 0.33 & 0.46 \\
$\mathrm{I}$ (va.serv/va) & 0.52 & 0.63 & 0.68 & 0.68 & 0.74 & 0.85 \\
$\mathrm{u}$ & 1.71 & 5.01 & 7.55 & 10.90 & 16.14 & 33.16 \\
qexport & 0.01 & 0.09 & 0.20 & 0.20 & 0.30 & 0.63 \\
numcompfam & 2.05 & 2.46 & 2.61 & 2.62 & 2.78 & 3.15 \\
trust & 3.03 & 3.17 & 3.25 & 3.26 & 3.35 & 3.63 \\
pupop1000 & 0.00 & 0.30 & 1.38 & 3.20 & 3.28 & 20.52 \\
percsup.m & 0.00 & 0.00 & 30.68 & 31.92 & 52.43 & 100.00 \\
percsup.c & 0.00 & 17.25 & 42.40 & 41.95 & 63.14 & 100.00 \\
$\log$ (dep/pop) & 1.35 & 1.78 & 2.20 & 2.11 & 2.38 & 3.09 \\
I(va/1000) & 1.27 & 4.21 & 6.22 & 10.04 & 10.18 & 112.10 \\
lrpro & 0.25 & 0.43 & 0.49 & 0.52 & 0.59 & 1.82 \\
percsup.agr & 0.07 & 0.38 & 0.59 & 0.55 & 0.73 & 0.92 \\
log(ag/pop) & -8.98 & -8.01 & -7.73 & -7.83 & -7.62 & -7.32 \\
pupop1000:percsup.m & 0.00 & 0.00 & 28.90 & 158.40 & 121.10 & 1666.00 \\
pupop1000:percsup.c & 0.00 & 0.00 & 35.85 & 107.50 & 104.00 & 1949.00 \\
pupop1000:percsup.agr & 0.00 & 0.18 & 0.56 & 1.41 & 1.53 & 15.07 \\
\hline
\end{tabular}




\section{Full estimation results}

\section{C.1 GGLS Random Effects panel estimation results without spatial correction}

\begin{tabular}{rrrrr}
\hline & coef & $\mathrm{se}$ & $\mathrm{t}$ & $\mathrm{pt}$ \\
\hline (Intercept) & -7.232032 & 1.720103 & -4.204418 & 0.000035 \\
$\log$ (Ydproc) & 1.156512 & 0.165342 & 6.994670 & 0.000000 \\
$\mathrm{I}$ (pop25.54/popover60) & 0.268546 & 0.119293 & 2.251143 & 0.025149 \\
$\mathrm{NO}$ & -0.051496 & 0.011580 & -4.447068 & 0.000013 \\
$\mathrm{NE}$ & 0.045594 & 0.055319 & 0.824209 & 0.410520 \\
$\mathrm{SU}$ & -0.255475 & 0.054661 & -4.673777 & 0.000005 \\
$\mathrm{IS}$ & -0.288996 & 0.064639 & -4.470903 & 0.000011 \\
dum98 & -0.094306 & 0.012889 & -7.316894 & 0.000000 \\
dum99 & -0.036897 & 0.009717 & -3.797031 & 0.000179 \\
$\mathrm{I}($ den/1000) & 0.102903 & 0.051126 & 2.012731 & 0.045097 \\
$\mathrm{I}($ va.indutot/va) & 0.405786 & 0.442339 & 0.917366 & 0.359738 \\
$\mathrm{I}$ (va.serv/va) & 0.368092 & 0.434076 & 0.847990 & 0.397165 \\
$\mathrm{u}$ & -0.000067 & 0.001900 & -0.035110 & 0.972017 \\
qexport & 0.022075 & 0.092149 & 0.239558 & 0.810848 \\
numcompfam & 0.016147 & 0.109742 & 0.147132 & 0.883133 \\
trust & 0.510440 & 0.125794 & 4.057747 & 0.000064 \\
pupop1000 & 0.134755 & 0.033928 & 3.971815 & 0.000091 \\
percsup.m & 0.002976 & 0.001112 & 2.676534 & 0.007876 \\
percsup.c & 0.000725 & 0.000772 & 0.938466 & 0.348811 \\
log(dep/pop) & 0.167496 & 0.051477 & 3.253771 & 0.001278 \\
$\mathrm{I}$ (va/1000) & 0.002882 & 0.001207 & 2.386959 & 0.017650 \\
lrpro & 0.014176 & 0.023118 & 0.613210 & 0.540234 \\
percsup.agr & 0.117385 & 0.134327 & 0.873875 & 0.382933 \\
log(ag/pop) & 0.167453 & 0.054103 & 3.095078 & 0.002166 \\
pupop1000:percsup.c & -0.000477 & 0.000135 & -3.522188 & 0.000499 \\
pupop1000:percsup.agr & -0.114299 & 0.036413 & -3.138982 & 0.001876 \\
\hline & & & & \\
pupop1000:percsup.m & -0.001326 & 0.000303 & -4.377530 & 0.000017 \\
\hline
\end{tabular}




\section{C.2 Spatial lag model (SAR) without Social Capital vari- ables}

\begin{tabular}{rrrrr}
\hline & coef & $\mathrm{se}$ & $\mathrm{z}$ & $\mathrm{pz}$ \\
\hline $\log$ (Ydproc) & 1.2750 & 0.1751 & 7.2838 & 0.0000 \\
$\log ($ dep/pop) & 0.0791 & 0.0487 & 1.6237 & 0.1044 \\
$\mathrm{I}$ (pop25.54/popover60) & 0.1969 & 0.1209 & 1.6281 & 0.1035 \\
$\mathrm{I}(\mathrm{va} / 1000)$ & 0.0027 & 0.0013 & 2.0554 & 0.0398 \\
$\mathrm{u}$ & -0.0003 & 0.0018 & -0.1422 & 0.8870 \\
qexport & 0.0869 & 0.0830 & 1.0465 & 0.2953 \\
$\mathrm{I}($ va.serv/va) & 0.3667 & 0.4342 & 0.8446 & 0.3983 \\
$\mathrm{I}($ va.indutot/va) & 0.5049 & 0.4444 & 1.1360 & 0.2560 \\
$\mathrm{I}($ den/1000) & 0.0727 & 0.0550 & 1.3227 & 0.1859 \\
numcompfam & 0.0522 & 0.1065 & 0.4899 & 0.6242 \\
$\operatorname{lrpro}$ & 0.0138 & 0.0213 & 0.6492 & 0.5162 \\
$\log ($ ag/pop) & 0.1299 & 0.0507 & 2.5615 & 0.0104 \\
inef & -0.0392 & 0.0134 & -2.9309 & 0.0034 \\
dum98 & -0.0657 & 0.0118 & -5.5488 & 0.0000 \\
dum99 & -0.0178 & 0.0093 & -1.9169 & 0.0553 \\
$\mathrm{NO}$ & 0.1239 & 0.0503 & 2.4616 & 0.0138 \\
$\mathrm{NE}$ & 0.0723 & 0.0486 & 1.4888 & 0.1365 \\
$\mathrm{SU}$ & -0.2233 & 0.0636 & -3.5088 & 0.0004 \\
$\mathrm{IS}$ & -0.1792 & 0.0732 & -2.4485 & 0.0143 \\
trust & 0.2481 & 0.1337 & 1.8555 & 0.0635 \\
$\mathrm{rho}$ & 0.1730 & 0.0314 & 5.5138 & 0.0000 \\
\hline
\end{tabular}




\section{C.3 Spatial error model (SEM) with Social Capital variables}

\begin{tabular}{rrrrr}
\hline & coef & $\mathrm{se}$ & $\mathrm{z}$ & $\mathrm{pZ}$ \\
\hline $\log ($ Ydproc) & 1.2240 & 0.1722 & 7.1073 & 0.0000 \\
$\log ($ dep/pop) & 0.0738 & 0.0461 & 1.5992 & 0.1098 \\
$\mathrm{I}$ (pop25.54/popover60) & 0.2046 & 0.1210 & 1.6905 & 0.0909 \\
$\mathrm{I}(\mathrm{va} / 1000)$ & 0.0032 & 0.0013 & 2.4845 & 0.0130 \\
$\mathrm{u}$ & -0.0013 & 0.0018 & -0.7136 & 0.4755 \\
qexport & 0.0426 & 0.0817 & 0.5216 & 0.6020 \\
$\mathrm{I}($ va.serv/va) & 0.3719 & 0.4409 & 0.8435 & 0.3989 \\
$\mathrm{I}$ (va.indutot/va) & 0.4555 & 0.4431 & 1.0281 & 0.3039 \\
$\mathrm{I}($ den/1000) & 0.1033 & 0.0572 & 1.8073 & 0.0707 \\
numcompfam & 0.0542 & 0.1068 & 0.5074 & 0.6119 \\
lrpro & 0.0131 & 0.0206 & 0.6343 & 0.5259 \\
log(ag/pop) & 0.1223 & 0.0468 & 2.6144 & 0.0089 \\
inef & -0.0527 & 0.0130 & -4.0540 & 0.0001 \\
dum98 & -0.0778 & 0.0106 & -7.3466 & 0.0000 \\
dum99 & -0.0250 & 0.0080 & -3.1192 & 0.0018 \\
$\mathrm{NO}$ & 0.0691 & 0.0601 & 1.1498 & 0.2502 \\
$\mathrm{NE}$ & 0.1031 & 0.0540 & 1.9105 & 0.0561 \\
$\mathrm{SU}$ & -0.2682 & 0.0609 & -4.4028 & 0.0000 \\
$\mathrm{IS}$ & -0.2868 & 0.0716 & -4.0067 & 0.0001 \\
trust & 0.5257 & 0.1406 & 3.7396 & 0.0002 \\
pupop1000 & 0.1216 & 0.0374 & 3.2511 & 0.0011 \\
percsup.m & 0.0027 & 0.0012 & 2.1617 & 0.0306 \\
percsup.c & 0.0008 & 0.0009 & 0.9142 & 0.3606 \\
percsup.agr & 0.0476 & 0.1474 & 0.3227 & 0.7469 \\
pupop1000:percsup.c & -0.0005 & 0.0002 & -3.3669 & 0.0008 \\
pupop1000:percsup.m & -0.0012 & 0.0003 & -3.6655 & 0.0002 \\
lambda & -0.5358 & 0.3690 & -1.4520 & 0.1465 \\
\hline & & & &
\end{tabular}




\section{C.4 Spatial error model (SEM) without Social Capital vari- ables}

\begin{tabular}{rrrrr}
\hline & coef & $\mathrm{se}$ & $\mathrm{z}$ & $\mathrm{pz}$ \\
\hline $\log$ (Ydproc) & 1.3459 & 0.1757 & 7.6594 & 0.0000 \\
$\log ($ dep/pop) & 0.0787 & 0.0469 & 1.6793 & 0.0931 \\
$\mathrm{I}$ (pop25.54/popover60) & 0.2073 & 0.1205 & 1.7208 & 0.0853 \\
$\mathrm{I}(\mathrm{va} / 1000)$ & 0.0024 & 0.0013 & 1.7754 & 0.0758 \\
$\mathrm{u}$ & -0.0010 & 0.0018 & -0.5502 & 0.5822 \\
qexport & 0.0826 & 0.0832 & 0.9929 & 0.3208 \\
$\mathrm{I}($ va.serv/va) & 0.4062 & 0.4320 & 0.9403 & 0.3470 \\
$\mathrm{I}($ va.indutot/va) & 0.5533 & 0.4435 & 1.2475 & 0.2122 \\
$\mathrm{I}($ den/1000) & 0.0758 & 0.0558 & 1.3570 & 0.1748 \\
numcompfam & 0.0765 & 0.1059 & 0.7221 & 0.4702 \\
$\operatorname{lrpro}$ & 0.0116 & 0.0208 & 0.5577 & 0.5771 \\
$\log ($ ag/pop) & 0.1391 & 0.0477 & 2.9190 & 0.0035 \\
inef & -0.0420 & 0.0136 & -3.0877 & 0.0020 \\
dum98 & -0.0792 & 0.0109 & -7.2395 & 0.0000 \\
dum99 & -0.0238 & 0.0083 & -2.8802 & 0.0040 \\
$\mathrm{NO}$ & 0.1650 & 0.0508 & 3.2510 & 0.0011 \\
$\mathrm{NE}$ & 0.0946 & 0.0491 & 1.9265 & 0.0540 \\
$\mathrm{SU}$ & -0.2769 & 0.0645 & -4.2929 & 0.0000 \\
$\mathrm{IS}$ & -0.2276 & 0.0743 & -3.0635 & 0.0022 \\
trust & 0.3258 & 0.1357 & 2.4011 & 0.0163 \\
lambda & -0.5162 & 0.3665 & -1.4086 & 0.1589 \\
\hline
\end{tabular}

